Scientific papers

\title{
Effect of indomethacin on swelling, lymphocyte influx, and cartilage proteoglycan depletion in experimental arthritis
}

\author{
E R PETTIPHER ${ }^{1}$ B HENDERSON ${ }^{1 *}$ J C W EDWARDS ${ }^{2}$ AND G A HIGGS ${ }^{1}$
}

From the ${ }^{1}$ Department of Pharmacology, Wellcome Research Laboratories, Beckenham, Kent; and the ${ }^{2}$ Department of Rheumatology Research, University College and Middlesex School of Medicine, London

SUMMARY The effects of indomethacin on antigen induced arthritis in rabbits have been investigated. Arthritis was induced in the knee joints of sensitised rabbits by intra-articular injection of antigen. Swelling of the joints was measured for 14 days after antigen challenge, and groups of animals were killed on days 1,7 , or 14 for collection of synovial fluids and tissues. Indomethacin $\left(1 \mathrm{mg} / \mathrm{kg}\right.$, three times daily) reduced joint swelling and the prostaglandin $E_{2}$ concentrations in synovial fluid. In addition, indomethacin increased the loss of proteoglycan from articular cartilage and the numbers of lymphocytes in the inflamed synovial lining. These findings suggest that the symptomatic benefits of indomethacin and related drugs in inflammatory arthritis may be achieved at the expense of significant adverse effects on joint tissues.

The so called 'non-steroidal anti-inflammatory drugs', which include aspirin, phenylbutazone, and indomethacin, are widely prescribed for all forms of synovitis, whether due to mechanical irritation (osteoarthritis), crystal deposition (gout and pseudogout), or a disturbance of the immune response as is postulated in rheumatoid arthritis. This group of drugs is characterised by a common pharmacological activity-inhibition of the synthesis of prostaglandins in inflamed tissues-and this specific mechanism accounts for their analgesic, antipyretic, and anti-inflammatory properties. ${ }^{1}$ In the clinic it is recognised that these drugs ease pain and diminish swelling, but there is no good evidence that they halt the progression of chronic erosive arthritis. ${ }^{2}$ Indeed, there has long been a suspicion that non-steroidal anti-inflammatory drugs may exacerbate some features of arthritis. For example, in primary osteoarthritis of the human hip a correlation has been reported between non-steroidal anti-inflammatory drug treatment and acetabular bone destruction. ${ }^{4}$ Furthermore, it has been shown

Accepted for publication 6 January 1989.

Correspondence to Dr E R Pettipher, Department of Pharmacology, Wellcome Research Laboratories, Langley Court, South Eden Park Road, Beckenham, Kent BR3 3BS.

*Present address: Celltech Limited, 216 Bath Road, Slough, Berkshire SL1 4EN. that non-steroidal anti-inflammatory drugs suppress chondrocyte proteoglycan synthesis and increase cartilage degeneration in vitro. ${ }^{5}$ In an in vivo model of granuloma induced cartilage degradation in mice indomethacin enhanced cartilage matrix destruction. ${ }^{6}$ In this study we investigated the effects of indomethacin on swelling, prostaglandin synthesis, cartilage proteoglycan loss, and lymphocyte influx in antigen induced arthritis in rabbits. This model was chosen because of its close similarity to rheumatoid arthritis in terms of cellular infiltration and structural changes in the joint. Some of these results have been reported to the British Pharmacological Society. ${ }^{7}$

\section{Materials and methods}

INDUCTION OF ANTIGEN INDUCED

A R T H R I T IS

Seventy adult male New Zealand White rabbits $(2 \cdot 5-3.0 \mathrm{~kg})$ were immunised intradermally with $4 \mathrm{mg}$ ovalbumin (Sigma, Poole, Dorset) in $1 \mathrm{ml}$ Freund's complete adjuvant (Gibco, Paisley, Scotland). Animals were reimmunised 14 days later in the same way. Five days after the second immunisation arthritis was induced in one knee joint by intra-articular injection of $5 \mathrm{mg}$ ovalbumin in 1 ml sterile saline. ${ }^{89}$ The contralateral knee joint was injected with sterile saline and served as a withinanimal control. The animals were divided into two 
groups of 35 . One group received oral doses of $1 \mathrm{mg} / \mathrm{kg}$ indomethacin (Merck, Sharp and Dohme. Hoddesdon, Herts) in aqueous solution at intervals of eight hours (8.00 am, $4.00 \mathrm{pm}$, and 12 midnight), while control animals received vehicle alone. Joint diameters were measured periodically with calipers, on a randomised blind basis for up to 14 days after antigen challenge.

COLLECTION OF SYNOVIAL FLUID

Groups of rabbits were killed 1, 7, or 14 days after antigen challenge. Sterile isotonic saline $(1 \mathrm{ml})$ was injected into both knee joints of each animal before the joints were opened and the resultant joint washes taken for leucocyte and rice body counts and estimations of prostaglandin $E_{2}$ concentrations by specific radioimmunoassay. ${ }^{10}$

\section{CARTILAGE PROTEOGLYCAN}

MEA S URE MENTS

The articular cartilage was dissected from the ends of both femurs and the proteoglycan content determined by assay of sulphated glycosaminoglycans (the heteropolysaccharide side chains of proteoglycan) after digestion with papain (Sigma) for one to two hours at $65^{\circ} \mathrm{C}$. Glycosaminoglycans were measured by the 1,9-dimethylmethylene blue binding assay. ${ }^{11}$ The proteoglycan content of cartilage was expressed as $\mu \mathrm{g}$ glycosaminoglycan $/ \mathrm{mg}$ wet weight or dry weight of tissue.

\section{HISTOLOGICAL ASSESSMENT OF SYNOVIAL} TISS UES

The detailed method of histological assessment is described elsewhere. ${ }^{12}$ Briefly, after removal of synovial fluid and articular cartilage the femur was excised at mid-shaft, and the distal femur with surrounding synovial tissue and patella was decalcified in buffered formic acid. Blocks ( $2 \mathrm{~mm}$ thick) were cut from decalcified specimens at right angles to the femoral shaft and passing through the upper third of the patella and the posterior articular surface of the condyles. These blocks were embedded in paraffin for conventional sectioning and staining with haematoxylin and eosin. Sections were examined with a $\times 40$ objective and a $1 \mathrm{~cm}$ square graticule divided into square millimetres. Lymphocytes and polymorphonuclear leucocytes were counted in 10 bands of tissue $250 \mu \mathrm{m}$ wide at $2.5 \mathrm{~mm}$ intervals along the tissue surface running from the synovial surface to deep fibrous tissue.

\section{Results}

Intra-articular injection of antigen induced an increase in joint diameter of 5-6 mm after 24 hours.

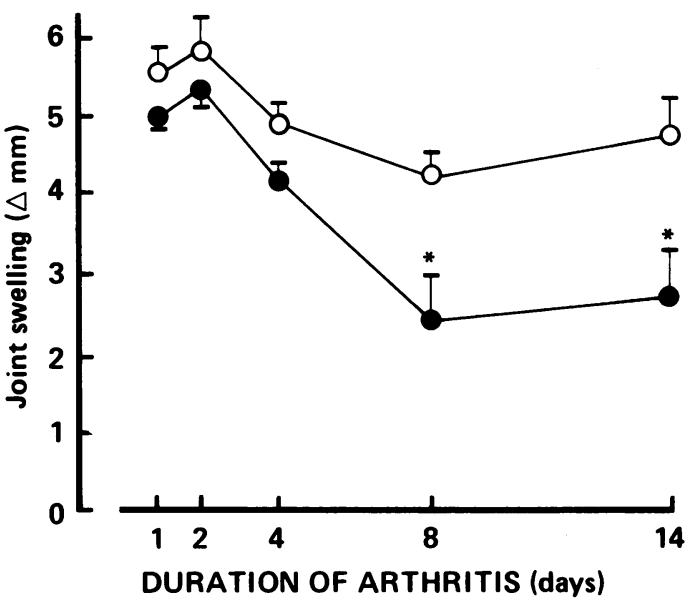

Fig. 1 Effect of indomethacin on joint swelling in antigen induced arthritis in rabbits. Antigen was injected intra-articularly on day 0 in groups of control (O) and indomethacin treated (O) animals. Indomethacin (1 $\mathrm{mg} / \mathrm{kg}$ ) was administered orally in aqueous solution three times daily (8.00 am, $4.00 \mathrm{pm}, 12$ midnight). Each point is the mean of five observations and the bars represent 1 SEM; ${ }^{*}$ indicates $p<0.02$ compared with controls.

Swelling declined slightly after four days but persisted at approximately $5 \mathrm{~mm}$ for up to 14 days (Fig. 1). Indomethacin did not prevent the initial swelling but significantly reduced swelling between eight and 14 days by about $50 \%$ (Fig. 1).

Synovial fluids from control animals contained up to $10 \mathrm{ng} / \mathrm{ml}$ prostaglandin $\mathrm{E}_{2}$ at 24 hours, which declined to about $3 \mathrm{ng} / \mathrm{ml}$ after 14 days. At both times indomethacin significantly reduced prostaglandin $E_{2}$ concentrations (Fig. 2). After antigen challenge there was a rapid accumulation of leucocytes in the synovial fluid and leucocyte numbers remained raised at between $5 \times 10^{6}$ and $2 \times 10^{7}$ cells $/ \mathrm{ml}$ for up to 14 days. Indomethacin treatment did not significantly alter the total number of $\frac{D}{O}$ leucocytes in the fluid at any time. Microscopic examination of the synovial fluid showed the pres- $N$ ence of 'rice bodies', which are thought to be composed of a mixture of fibrin and detached fragments of synovial tissue. ${ }^{13} 14$ Synovial fluids $\mathrm{C}$ from arthritic joints from animals killed at day 70 contained $1.4(0.1) \times 10^{4}$ rice bodies $/ \mathrm{ml}$ (mean $(\mathrm{SEM}) ; n=5)$, and rice bodies were increased $(14 \cdot 1 \stackrel{\oplus}{\overparen{Q}}$ $\left.(3.4) \times 10^{4} ; n=5\right)$ in fluids from indomethacin treated ? animals.

The glycosaminoglycan content of articular $\frac{\vec{\Phi}}{\Phi}$ cartilage from control joints contained $31 \cdot 1(1 \cdot 7) \stackrel{\rho}{ه}$

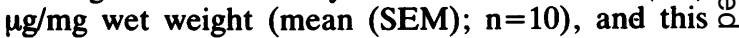
was unaltered during the course of the arthritis. 


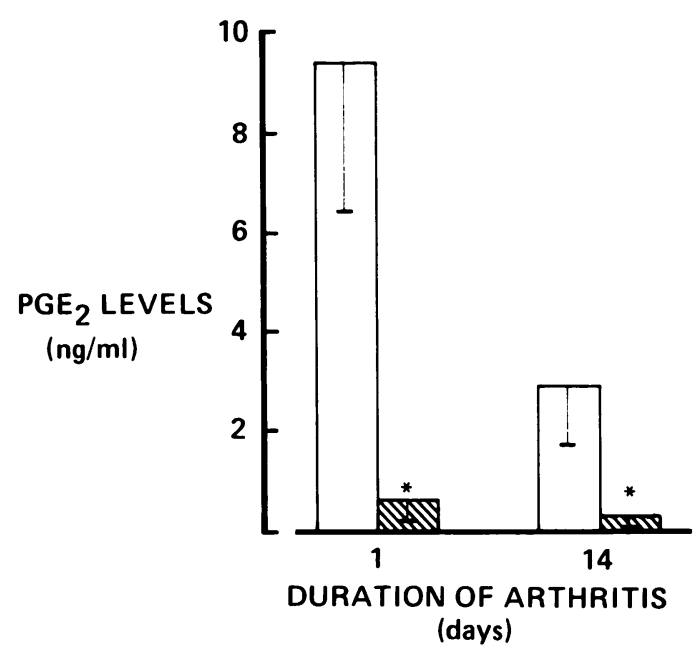

Fig. 2 Concentrations of prostaglandin $E_{2}\left(P G E_{2}\right)$ in synovial fluids collected from antigen injected joints of control (open columns) or indomethacin treated (hatched columns) rabbits. Each histogram is the mean of five observations and the bars represent 1 SEM; ${ }^{*}$ indicates $p<0.01$ compared with controls.

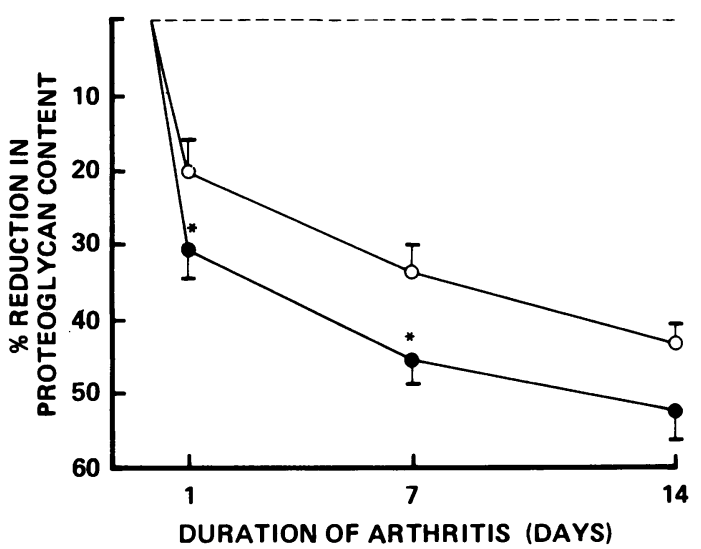

Fig. 3 Proteoglycan loss from the articular cartilage of antigen injected knee joints of control $(O)$ and indomethacin treated (O) rabbits. Each point is the mean of 5-18 observations and the bars represent I SEM; ${ }^{*}$ indicates $p<0.05$ compared with controls.

The glycosaminoglycan content of articular cartilage taken from arthritic joints decreased progressively from days 1 to 14 , reaching a loss of more than $40 \%$ of the proteoglycan by day 14 (Fig. $3)$. At days 1,7 , and 14 indomethacin treatment caused a greater proteoglycan loss (Fig. 3). The same quantitative result was obtained when proteoglycan loss was expressed as a function of wet or dry
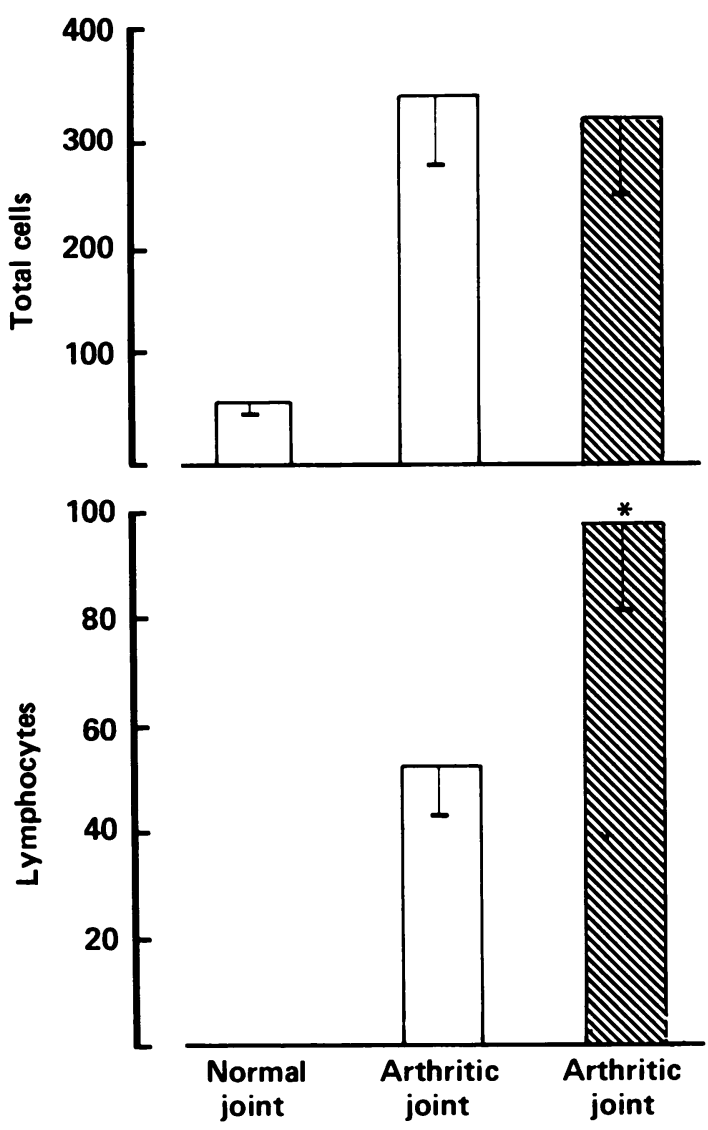

Fig. 4 Total cells (upper panel) and lymphocytes (lower panel) counted in 10 bands of synovial membrane (250 $\mathrm{um}$ wide) taken from the antigen injected joints of control (open columns) and indomethacin treated (hatched columns) rabbits 14 days after antigen challenge. Each column is the mean of 6-19 observations and the bars represent 1 SEM; ${ }^{*}$ indicates $p<0.05$ compared with controls.

weight of cartilage, indicating that the indomethacin effect could not be explained by increased hydration of this tissue.

Histological examination of the inflamed synovium from arthritic joints 14 days after antigen challenge showed a considerable thickening of the synovial membrane with an increase of approximately sevenfold in the total numbers of cells and the appearance of large numbers of lymphocytes (Fig. 4). Indomethacin treatment did not significantly change the total numbers of cells but almost doubled the lymphocyte count (Fig. 4).

Significant numbers of polymorphonuclear leucocytes in the synovial lining were only seen at day 1 
after antigen challenge, and this was unaltered by indomethacin treatment. Inflamed synovial tissue from control animals contained 167 (18) polymorphonuclear leucocytes/10 bands (mean (SEM); $\mathrm{n}=5$ ), while tissue from indomethacin treated animals contained $171 \quad(38) \quad(n=5)$. Very few polymorphonuclear leucocytes were seen at days 4 , 7 , or 14 .

\section{Discussion}

The results reported in this study confirm that indomethacin reduces joint swelling and synovial fluid prostaglandin $E_{2}$ concentrations in antigen induced arthritis. ${ }^{15}$ Probably, inhibition of prostaglandin synthesis contributes to the reduction of swelling as prostaglandin $E_{2}$ enhances plasma extravasation and oedema. ${ }^{1}$ We have now shown, however, that indomethacin accelerates proteoglycan loss from articular cartilage in a model of immune arthritis which closely resembles human rheumatoid disease in terms of joint histopathology. The increased numbers of rice bodies in the synovial fluid also suggest increased degenerative activity.

Possibly, the enhanced cartilage damage in response to indomethacin treatment may be due to reduction in the quantity of inflammatory exudate, which contains protease inhibitors. This is unlikely, however, as indomethacin increased proteoglycan depletion at day 1 , a time when there was no reduction in joint swelling (and presumably, exudate volume).

An alternative explanation is that inhibition of the production of prostaglandin $\mathrm{E}_{2}$, which is immunosuppressive, leads to greater cytokine generation and, consequently, greater joint destruction. Prostaglandin $E_{2}$ is known to suppress and indomethacin enhance the production of interleukin 1 from mononuclear cells. ${ }^{16}$ The increased concentration of interleukin 1 is likely to have deleterious effects on the integrity of the articular cartilage as interleukin 1 is a potent inducer of cartilage degradation in vivo. The increased production of interleukin 1 may, in turn, lead to greater infiltration or proliferation of lymphocytes, or both. Alternatively, the inhibition of prostaglandin $E_{2}$ synthesis may contribute directly to the increase in lymphocyte numbers as prostaglandin $E_{2}$ inhibits lymphocyte proliferation. ${ }^{17}$ Furthermore, Lewis and Barrett have shown that indomethacin dramatically enhances the proliferation of human mononuclear cells in response to mitogens. ${ }^{18}$ An increased number of activated lymphocytes may contribute to cartilage matrix breakdown by interacting with antigen presenting cells and consequently causing the generation of more cytokines. The enhancement of cartilage proteoglycan loss seen in indomethacin treated animals occurred before major lymphocyte $\overrightarrow{\bar{*}}$ influx was evident, however, suggesting that other mechanisms are involved in the early stages.

The causal relations between cartilage damage $\overline{\bar{m}}$. and lymphocyte influx in chronic synovitis are unclear. Muirden and Mills suggested an inverse temporal relation between tissue destruction andes lymphocyte infiltration. ${ }^{19}$ Observations on human $\overrightarrow{0}$ tissue usually involve assessment of cell density rather than total cell numbers, however. Tissue undergoing damage to matrix is commonly oedematous and expanded by fibrin deposits. Lymphocyte density may be reduced in such tissues, being dilutedobo locally by acellular or necrotic material, whereasio total numbers may be high. In our study the fulf thickness of synovium was analysed, giving a measure of total cell numbers in the joint. The fact? that total cell numbers were not changed significantly $\vec{\Delta}$ by indomethacin treatment, despite the increase in lymphocyte numbers, suggests that the numbers of infiltrating monocytes or proliferating fibroblasts might have been reduced. Because lymphocytes formed a relatively small proportion of the tota cells, however, the fractional reduction of other cells was small and cannot be considered significant on the present evidence.

We conclude from these studies that indometha cin, although having clear therapeutic effects ir $\mathbb{Z}$ reducing the symptoms of arthritis, may actually exacerbate some of the chronic degenerative aspects of immune arthritis. These findings emphasise the need for new treatments to modulate tissue degeno eration to be used as an adjunct to the current anti inflammatory and analgesic drugs.

\section{References}

1 Higgs G A, Moncada S, Vane J R. Eicosanoids in inflamma-윽 tion. Ann Clin Res 1984; 16: 287-99.

2 Wright V, Amos R. Do drugs change the course of rheumatoido arthritis? $\mathrm{Br}$ Med $J$ 1980; 280: 964-6.

3 Dudley Hart F, Huskisson E C. Non-steroidal anti-inflamma-N tory drugs: current status and rational therapeutic use. Drugs 1984; 27: 232-55.

4 Newman N M, Ling R S M. Acetabular bone destruction related to non-steroidal anti-inflammatory drugs. Lancet 1985 ;
ii: $11-13$.

5 Brandt K D. Effects of non-steroidal anti-inflammatory drug®o on chondrocyte metabolism in vitro and in vivo. $\mathrm{Am} \mathrm{J} \mathrm{Med}$ 1987; 83: 29-34.

6 Bottomley K M K, Griffiths R J, Rising T J, Steward A. A modified mouse air pouch model for evaluating the effects of compounds on granuloma-induced cartilage degradation. $\mathrm{Br} \underset{\mathrm{D}}{\mathrm{P}}$ Pharmacol 1988; 93: 627-35.

7 Pettipher E R, Henderson B, Edwards J C W, Higgs G A $\overrightarrow{\mathbb{D}}$ Indomethacin enhances proteoglycan loss from articular cartil $\varrho$ age in antigen-induced arthritis. BrJ Pharmacol 1988; 94: 341P 8 Dumonde D C, Glynn L E. The production of arthritis in 
rabbits by an immunological reaction to fibrin. $\overline{B r J}$ Exp Pathol 1962; 43: 373-83.

9 Pettipher E R, Higgs G A, Henderson B. Interleukin-1 induces leukocyte infiltration and cartilage proteoglycan degradation in the synovial joint. Proc Natl Acad Sci USA 1986; 83: 8749-53.

10 Salmon J A. A radioimmunoassay for 6-keto-prostaglandin F1 . Prostaglandins 1978; 15: 383-97.

11 Farndale R W, Buttle D J, Barrett A J. Improved quantitation and discrimination of sulphated glycosaminoglycans by use of dimethylmethylene blue. Biochim Biophys Acta 1986; 883: 173-7.

12 Edwards J C W, Read N, Trefty B, Coulstock J, Henderson B. Morphometric analysis of antigen-induced arthritis in the rabbit. Br J Exp Pathol 1988; 69: 739-48.

13 Riese H. Die reishorperchen in tuberculos erkrankten. Synovalsachen. Deutsche Zeitschrift für Chirurgie 1895; 42: 1-7.

14 Popert A J, Scott D L, Wainwright A C, Walton K W, Williamson N, Chapman J H. Frequency of occurrence, mode of development, and significance of rice bodies in rheumatoid joints. Ann Rheum Dis 1982; 41: 109-17.

15 Blackham A, Farmer J B, Radziwonik H, Westwick J. The role of prostaglandins in rabbit monoarticular arthritis. $\mathrm{Br} J$ Pharmacol 1974; 51: 35-44.

16 Kunkel S L, Chensue S W, Phan S H. Prostaglandins as endogenous mediators of interleukin-1 production. $J$ Immunol 1986; 136: 186-92.

17 Goodwin J S, Bankhurst A D, Messner R P. Suppression of human $T$ cell mitogenesis by prostaglandin. Existence of a prostaglandin-producing suppressor cell. J Exp Med 1977; 146: 1719-34.

18 Lewis G P, Barrett M L. Immunosuppressive actions of prostaglandins and the possible increase in chronic inflammation after cyclo-oxygenase inhibitors. Agents Actions 1986; 19: 59-65.

19 Muirden K D, Mills K W. Do lymphocytes protect the rheumatoid joint? $\mathrm{Br}$ Med $J$ 1971; iv: 219-21. 